\title{
Research on Novel and Innovative Music Education Model based on Multiple Intelligences Theory and New Media
}

\author{
Li Xu ${ }^{1}$ \\ ${ }^{1}$ Jiangxi Science \& Technology Normal \\ University, \\ Nanchang,China
}

\begin{abstract}
With the rapid development of new media and education theories, the combination of the two aspects is urgently needed. In this paper, we conduct theoretical analysis on novel and innovative music education model based on multiple intelligences theory and new media. The theory of multiple intelligence education concept is to change too pay attention to the tendency of knowledge. The novelty of new media, not only in the form of new information carrier and communication channel, also include technological progress brings new propagation mode. Our proposed combined model will enhance the performance of the current teaching activity which is meaningful.
\end{abstract}

Keywords: Music Education; New Media; Multiple Intelligences; Multimedia Environment.

\section{Introduction}

Quality education and new curriculum reform started to become hot in China and the theory of multiple intelligences just for quality education and new curriculum reform provides a theoretical basis and research methods. Throughout the origin and development of the theory of multiple intelligences has many clues throughout the theory of multiple intelligences, make them become the interconnected network system, and blend with each other, one of the very important clues to watch, it's music, it is the origin of the theory of multiple intelligences, intelligence plays an important role in medium and the intelligent training. The theory of multiple

\author{
Fei $\mathrm{Li}^{2}$ \\ ${ }^{2}$ School of Music ,Jiangxi Science \& Technology \\ Normal University, \\ Nanchang,China
}

intelligence education concept is to change too pay attention to the tendency of knowledge. Emphasis on cultivating positive learning attitude means emphasis on the formation of emotional attitude values. Music education should not be just the single skill learning. More should pay attention to its aesthetic education, cultivate the students to understand and experience the beauty and creating beauty, evaluate ability, it pay more attention to cultivate and inspire, and making education beauty, intelligence and physique full scale development. Pay attention to the development of music understanding for a long time, will inevitably to reinforce students' aesthetic temperament and interest, better able to distinguish between right and wrong, discern beauty and ugliness [1]. Soul get purification, their emotional world get rich and perfect, make the music art in a unique manner infiltration in the healthy development of people, give a person with beautiful enjoyment and enlightenment, lets the student in the own and in person the quiet spring rain healthy and comprehensive development in the future [2].

To cultivate interest in music learning, interest is the best teacher which is the key to open the music hall, also invite swim music world athletic wing, can students develop interest in music, often influenced by the music teacher is quite deep, by creating music art education, exert a role of the aesthetic education infiltrate into music education [3]. Develop the students' interest, edify students' personality. So penetrating thoughts in music education, emotional education and virtue education, aesthetic 
education is quite important. The theory of multiple intelligences provides teachers with a positive objective understanding to the student, each student has sparkle and redeeming feature, teacher should from many aspects to understand students' specialty, and accordingly take suitable to the characteristics of effective method, make its special features are fully play. In the process of the concrete teaching practice, teachers should according to each student, the intelligence development level of different, encourage them to participate in the corresponding teaching activities, make every student have the opportunity to play their own intelligence, and guide students at the appropriate time, the advantages of intelligent migrated to weak intelligence, promote the all-round development of the intelligence [4]. In order to achieve the teaching goal, the teacher asked the students in the process of preparation before class need to help each other and learn from each other the process of intelligent play with exercise and finally achieved to make the students actively learn English in happy mood.

Therefore, to combine the state-of-the-art methodology into the traditional education pattern, in this paper, we conduct theoretical analysis on novel and innovative music education model based on multiple intelligences theory and new media. Music accomplishment is mainly refers to music appreciation and music activities to learn and master the music basic knowledge and basic skills, include music and appreciate hearing ability, expression ability and creation ability. Music literacy is an important part of students' comprehensive quality and the establishment of the aesthetic is not only beneficial to the students and conducive to the formation of professional quality which has important influence on emotional intelligence, for students career development is sustained, a positive impact. In the next sections, we will discuss this issue in detail.

\section{The Proposed Novel Model of Education}

The Concepts of Multiple Intelligences Theory. Human way of thinking is diverse and there may be more than 9 kinds of intelligence: language intelligence, mathematical logic intelligence, spatial intelligence, body - sports intelligence, music intelligence, interpersonal intelligence, intrapersonal intelligence and explore natural intelligence. Everyone has the nine aspects of intelligence, just with different level combination and play, and the appropriate education and training can make each kind of intelligence to a higher level. Education should, therefore, on the basis of the comprehensive development of intelligent, with wide variety of choices for everyone, inspire everyone potential intelligence level, full development of personality. The combined education model has the following advantages. (1) To promote the development of elementary education reform. Music ability itself is an important intelligence and the ability of music to improve for other subjects of study has a positive role in promoting, and contains rich aesthetic education resources. This kind of new education teaching mode, is bound to arouse music teaching idea, teaching goal, teaching content, teaching methods, teaching evaluation and other aspects of the change, then to promote music education reform development. (2) Promote multicultural education mode. Multiple intelligence education directly impact on the development of multicultural education, therefore, the requirement for teachers' quality is very high and therefore music teachers must have the innovation consciousness, first with the interdisciplinary knowledge and ability. (3) Is beneficial to optimize the music classroom teaching process, improve the quality of teaching, improve teaching effectiveness. The music classroom teaching under the guidance of the theory of multiple intelligences, can change the "closed" teaching inefficient state, is advantageous to the comprehensive development of students' quality, respect the diversity of 
students, the maximum develop the potential of students, make students get development most intelligent strengths. Help optimize the music in teaching process, improve the quality of teaching to improve teaching effectiveness.

For many years, our country school education has always been the students as the container of knowledge, music education is no exception, many teachers focus on the research teaching material analysis, teaching forms, teaching means and presented the logical structure of knowledge, rarely from the students themselves to pay attention to the effectiveness of learning. This is especially true in the classroom teaching, teaching is the center of the school work and classroom teaching is to develop potential and to develop intelligence, the implementation of quality education the main channel. However, look at the current classroom teaching in the implementation of quality education, the status quo of training innovative talents as you can see, it does not fully play a proper role. Are criticized the disadvantages of traditional teaching in classroom teaching still exists today, main show is lack of creativity and subjectivity to ignore, one-sided teaching efficiency is low, the student development and so on. From the point of some drawbacks in the current classroom teaching, whether it is the lack of creativity, neglect of the subjectivity, teaching efficiency is low, one-sided, or student development is with the spirit in which the theory of multiple intelligences. For piano teaching in normal universities, therefore, to explore a teaching of the professional characteristics of the road is very important. In today's society is a pluralistic information society, it requires the all-round development of multiple intelligence and personality, everyone can fully display. Therefore, to make music education to adapt to today's rapidly developing society, we must first update the old curriculum system, establish new curriculum system, and on the basis of the theory of multiple intelligences to several other memory enrichment to the course, in the field of intelligent make new curriculum reflects the diversity of human intelligence.

The Advances of New Media. The novelty of new media, not only in the form of new information carrier and communication channel, also include technological progress brings new propagation mode. In the rise and development of the new media, to all areas of human society have a profound impact, including education field. Constructivism, as a kind of classic cognitive theory under the background of modern education technology especially in the new media environment, coruscate gives new vitality. Music itself can create a variety of situations, for students in the traditional multimedia environment and teachers can use music CD, video and other data presented to students. However, because the content of music appreciation course involves is various, work related Chinese and foreign historical and cultural background is complex, schools in the database of the general will not be able to find all. Vast online audio and video media and make full use of the Internet information, you can construct an ideal teaching situation. In the following figure one, we show the popular sample of using the multimedia and new media technique.

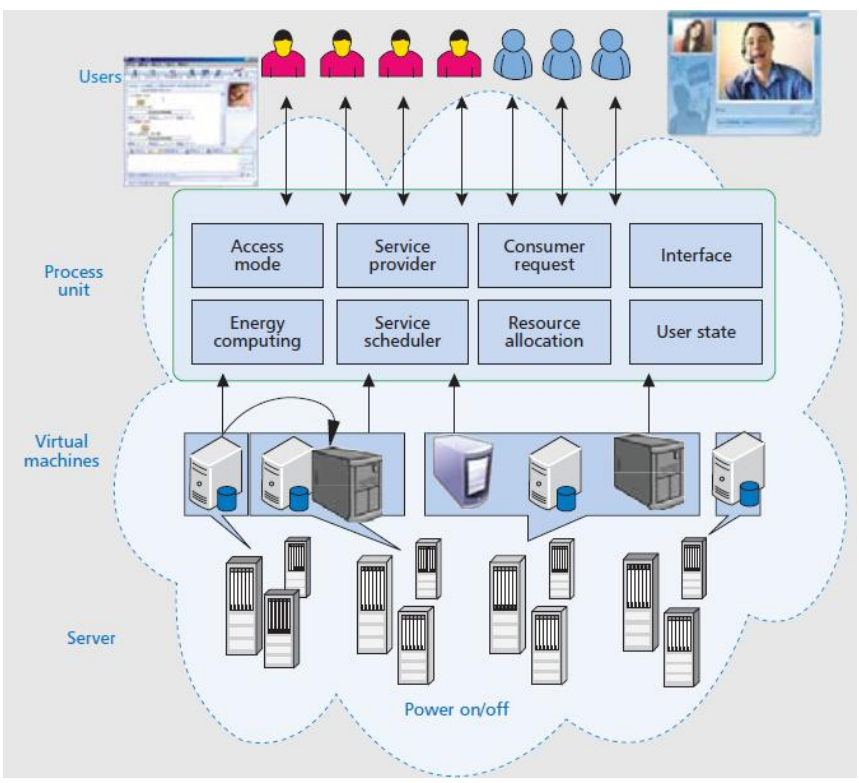

Fig. 1The Adopted Sample for New Media Applications 
Digital technology has been inexorably penetrated into every corner of life and makes people in a very low cost and a huge amount of information between the equals sign. Digital TV, digital $C D$, such as the outcome of the digital revolution, make information in a simple way of communication, access, with greater capacity in a more personal way to communicate with the receiver. New media music forms are: digital audio and video, computer music and music network, etc. Based on the digital technology is the main characteristic of new media art of music and publicity, timeliness and virtual sex epidemic, interactive and comprehensive. New media increasingly powerful make whole art from ideology to the creative practice are far beyond the limitations of the traditional music forms and contents revolutionary mutation also destined to happen. It not only changed the way music production and dissemination, has changed the whole art consumption. New media era makes network music culture become a new way to interpret the humanistic value of contemporary art. From music creation to digital images, the fusion of visual and auditory, make network music in the virtual image world has created a unique aesthetic features, aesthetic perception and expression, reveals the deeply cultural symbol meaning, forming the unique humanities color and create space. Simple interpersonal relationship is a two-way flow of people, between people and groups were replaced which makes people obtain needed information selectively. The traditional media in the present gradually tends to digital, information exchange between media increasingly performed by digital.

The Combined Innovative Teaching Model. Because of the influence of the traditional concept of intelligence, the former English listening teaching mainly develop the students' knowledge and skills, not pay attention to develop students' intelligence. Such teaching objectively promoted the development of the students' intelligence which is only on the language and logic of these two kinds of traditional intelligence, as for the music intelligence interpersonal intelligence, body movement and the development of self-cognition intelligence such as intelligence, basic didn't get attention. These potential students there would be no chance to be excited, cause the waste of education. Gardner's theory of multiple intelligences explicitly pointed out that successful education lies in cultivating potential right smart, fully develop its closed. Differ in thousands ways of students' personality, everyone has innate personality potential, teachers should make through the appropriate foreign language teaching and training students' every intelligent development to a higher level, and cultivate students find and solve the problem of method and ability, so that the students to be able to continuously acquire new knowledge, comprehensive development of lifelong learners. Symbol is one of the main features of music, sound and music is the most important two music symbols, left the sound, the beauty of music, cannot be without music, music heritage cannot continue. Music as a kind of highly abstract complex auditory symbol system, by the rhythm, tempo, strength, tone, color, depth and a series of elements of melody as its major means of expression. In the long-term development of ordering, music symbol of ideographic function is becoming more and more strict, the system, so people often call it "music language", like language which has a strong function of expression. In the theory of multiple intelligences, music as a medium is refers to the arts, including music, as an important intervention study of multiple intelligences. In the theory of multiple intelligences of eight kinds of intelligence, music intelligence is an important part of them and the media form and music intelligence in the relationship with the other seven kinds of intelligence and training and played an important role in media. Our proposed method has special meaning. 


\section{Conclusion}

In this paper, we conduct theoretical analysis on novel and innovative music education model based on multiple intelligences theory and new media. Music accomplishment is mainly refers to music appreciation and music activities to learn and master the music basic knowledge and basic skills, include music and appreciate hearing ability, expression ability and creation ability. New media increasingly powerful make whole art from ideology to the creative practice are far beyond the limitations of the traditional music forms and contents revolutionary mutation. The combined novel methodology will enhance the performance of music teaching activity significantly. We plan to conduct more test and theoretical analysis on the topic to modify and polish our present research.

\section{References}

[1] Action, Criticism, Education, et al. "Socialized Music": Historical Formations of Community Music through Social Rationales.[J]. Action Criticism \& Theory for Music Education.

[2] Colwell R. Response to David Elliott's "Music Education as/for Artistic Citizenship"[J]. Philosophy of Music Education Review, 2014, 22(1):105-108.

[3] Wright R. The Fourth Sociology and Music Education: Towards a Sociology of Integration.[J]. Action Criticism \& Theory for Music Education, 2014, 13.

[4] Silverman M, Davis S A, Elliott D J. Praxial music education: A critical analysis of critical commentaries[J]. International Journal of Music Education, 2014, 32(1):53-69. 